\title{
Population Genetics of Ochlerotatus eatoni (Diptera: Culicidae) Endemic Species to Two Macaronesian Islands
}

\author{
MAHNAZ KHADEM, YSABEL CONÇALVES, SANDRA MENDONÇA, AND RUBEN CAPELA
}

Centre for Macaronesian Studies, University of Madeira, Funchal 9000-Madeira, Portugal

J. Med. Entomol. 43(2): 232-237 (2006)

\begin{abstract}
Analyses of 11 isoenzyme loci of Ochlerotatus eatoni (Edwards, 1916), endemic to two Macaronesian Islands (Madeira and Tenerife, Canary Islands), revealed substantial genetic structure in the study populations. Samples from sites on the south and north of Madeira displayed a significant reduction of variability compared with those from central Madeira and Tenerife. The Tenerife population exhibited a severe deficit of heterozygosity with similar magnitude across all the loci examined. The complex pattern of variation in Oc. eatoni is because of interplay of breeding structure, genetic drift, and geographical and historical factors. From these findings, we concluded that island colonization by Oc. eatoni was not marked by founder effect.
\end{abstract}

KEY WORDS Ochlerotatus eatoni, endemism, population structure, Macaronesian Islands

Ochlerotatus eatoni (Edwards, 1916) (Diptera: Culicidae) was until recently classified as Aedes eatoni (Reinert 2000, Schaffner et al. 2001). Some members of the Aedes genus [such as Aedes aegypti (L.) and Aedes albopictus (Skuse)] have been intensively studied because of their efficiency in transmitting arbovirus diseases such as dengue and yellow fever (Powell et al. 1980, Tabachinck and Wallis 1985, Apostol et al. 1996, Paupy et al. 2004). These successful colonizers have spread worldwide from their native origin in tropical and subtropical areas (Smith 1956, Forattini 1986, Hawley 1988, Rai 1991), and their biology, ecology, population genetics, and evolution are well known. Recently, members of the subgenus Stegomyia also have been studied (Taafe Gaunt et al. 2004). In contrast, species of the genus Ochlerotatus are relatively poorly studied (Cook et al. 2005), and intraspecific population studies are particularly rare (Rey et al. 2001). Endemic to islands from two Macaronesian archipelagos (Madeira and the Canary Islands), $O c$. eatoni has a very limited geographical distribution. First described by Edwards (1916) in Monte (Madeira) and then by Clavero (1947) in Monte de las Mercedes (Tenerife, Canary), it was later found in other localities of the two islands (Capela 1981, Baez 1987). Oc. eatoni normally occurs in rural, urban, and forested areas and is only occasionally found inside houses. Oc. eatoni has a catholic choice of breeding sites, including both natural sites (tree holes and rock pools) and artificial sites (tires and plastic or metal bottles) (Y.C., personal communication). The host it feeds upon is unknown. However, Oc. eatoni does not show anthropophilic behavior and probably uses other vertebrates as blood sources (Y. Gonçalves).
The evolutionary biology of Oc. eatoni is of special interest because it represents two fundamental events: speciation and colonization within two islands. This study outlines a first attempt to shed light on evolutionary history of Oc. eatoni, by analyzing isoenzyme variations in five populations from Madeira and one population from Tenerife (Canary Islands).

\section{Materials and Methods}

Sampling Areas. Oc. eatoni populations were sampled from Madeira and Tenerife islands. The size of the islands is 740 and $2,034 \mathrm{~km}^{2}$, respectively.

Samples and Electrophoresis. Adult mosquitoes were collected from five localities in Madeira: Babosa (Bab) and Campanário (Cam) in the south, Queimadas (Que) and Chão do Ribeira (ChR) in the north, and Chão dos Louros (ChL) in the center (Fig. 1). Adults also were collected from one locality, Monte de las Mercedes, in Tenerife. Individuals were identified and kept at $-80^{\circ} \mathrm{C}$ until analysis. Populations were screened for their isoenzyme polymorphism, and 11 enzymes loci were tested: phosphogluconate dehydrogenas (Phi), adenylate kinase (Ak), phosphoglucoisomerase $(6 \mathrm{Pdh})$, glutamate oxaloacetate transaminases (Got), phosphoglucomutase (Pgm), $\alpha$-glycerophosphate dehydrogenase ( $\alpha$-Gpd), isocitrate dehydrogenase (Idh), malic dehydrogenaseNADP (Me), malic dehydrogenase-NAD (Mdh), esterase (Est), and peptidase (Pep). Starch gel electrophoresis was carried out according to Loukas and Krimbas (1980). Ak, Got, Idh, Est, and Pept were screened in Tris-boric-EDTA, $\mathrm{pH} 8$; Pgm, Me, and Mdh were screened in Tris-maleic-EDTA- $\mathrm{MgCl}_{2}, \mathrm{pH}$ 7.4; and 6Pdh and $\alpha$-Gpd were screened in Tris-citrate- 
(b)

(a)

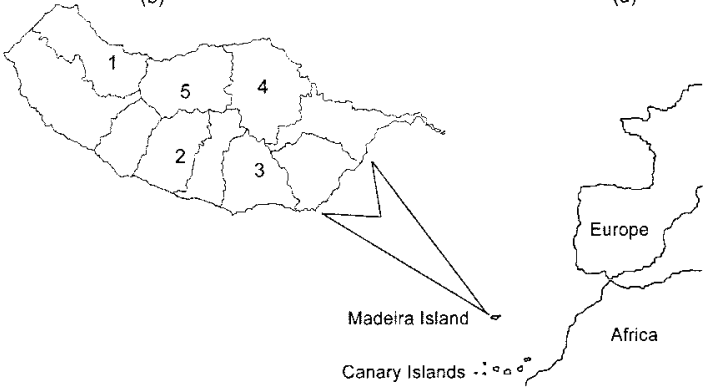

Fig. 1. (a) Geographical position of Madeira and the Canary Islands in relation to Africa and Europe. (b) Map of Madeira showing the five sampling localities: 1, Chão da Riberira (ChR); 2, Campanário (Cam); 3, Babosa (Bab); 4, Queimadas (Que); and 5, chão dos Louros (ChL).

EDTA, pH 8.5, buffer systems. Alleles were numbered according to their mobility relative to that of the most common allele.

Data Analysis. GENEPOP (version 3.3) software (Rousset and Raymond 1995) was used to analyze population parameters. $\mathrm{F}_{\mathrm{IS}}$ and $\mathrm{F}_{\mathrm{ST}}$ were calculated according to Weir and Cockerham (1984) and deviation from Hardy-Weinberg (HW) equilibrium caused by heterozygote deficiency or excess was estimated using Markov-chain algorithm of Guo and Thompson 1992. Linkage disequilibrium was estimated by Fisher test. Ohta SD statistic was used to determine the role of selection acting on pairs of loci (Ohta 1982). Fisher (1970) exact test was used to assess genetic differentiation between pairs of populations or groups. Number of effective migrants per generation $(\mathrm{Nm})$ was estimated by private allele method (Barton and Slatkin 1986) and by using the equation $\mathrm{Nm}=\left[\left(1 / \mathrm{F}_{\mathrm{ST}}\right)-1\right] / 4$ (Wright 1969).

\section{Results}

Variability and Tests of Disequilibrium. Of the 11 enzymes analyzed, only Pep was monomorphic in all the populations. The remaining 10 enzymes segregated between two (6-Pdh and Got) to seven (Pgm) alleles in the six geographical populations studied (Table 1). The level of variability measured by average number of alleles (a), percentage of polymorphism (p), and level of mean heterozygosity ( $\mathbf{H})$ differed among the populations Based on the endemic nature of the species studied and published data on genetic variability of nonendemic mosquito species (Giming 2000, Taaf et al. 2004), we divided the Madeira populations of Oc. eatoni into three groups: 1, populations Ch R, Cam, and Que that exhibited low level of variability $(\mathrm{p}=18.2-27.3$ and $\mathrm{H}=0.044-0.074)$; 2 , population Cam with intermediate level of variability ( $\mathrm{p}=$ 63.3 and $\mathrm{H}=0.118$ ); and 3, population $\mathrm{Ch} \mathrm{L}$ with high level of variability $(\mathrm{p}=77.7$ and $\mathrm{H}=0.194)$. The single population from Tenerife had high level of variability ( $\mathrm{p}=72.7$ and $\mathrm{H}=0.346$ ), similar to the central population (ChL) of Madeira (Table 1)
The inbreeding coefficient $\left(\mathrm{F}_{\text {IS }}\right)$ was used to measure any departure from $\mathrm{HW}$ equilibrium. Of 33 tests, 12 departed significantly from equilibrium, with Bonfferoni correction (Table 1), because of heterozygote deficiency. In the Tenerife population, all polymorphic loci had significant heterozygote deficiency, indicating the influence of inbreeding. In Madeira, six of the 24 polymorphic population/locus combinations were not at HW equilibrium. Me was the only locus with deficiencies in all the populations, except ChL and Bab. Considering all the loci, only one population (Que) did not show any departure from equilibrium.

The null hypothesis (genetic equilibrium) was rejected $(P<0.05)$ in five of 50 pairwise comparisons after analysis of nonrandom combinations of genotypic association between pairs of loci. These were between Phi-Pgm, Got-Pgm, and Ak-Mdh in the Tenerife population and between Phi-Pgm in ChR and ChL. High heterozygote deficiency in the Tenerife population may have been the cause of disequilibrium. Disequilibrium was detected between Phi-Pgm, 6PdhGot, and Got-Pgm. The Ohta test (Ohta 1982) was performed, and the total linkage disequilibrium $\left(\mathrm{D}_{\mathrm{IT}}\right)$ was divided between the indices of disequilibruim within populations $\left(\mathrm{D}_{\mathrm{IS}}, \mathrm{D}^{\prime}{ }_{\mathrm{IS}}\right)$ and between populations $\left(\mathrm{D}_{\mathrm{ST}}, \mathrm{D}_{\mathrm{ST}}^{\prime}\right)$. For all pairs of loci, $\mathrm{D}_{\mathrm{IS}}$ was lower than $\mathrm{D}_{\mathrm{ST}}$ and $\mathrm{D}^{\prime}{ }_{\text {IS }}$ was greater than $\mathrm{D}_{\mathrm{ST}}^{\prime}$ (data not presented), indicating a role of genetic drift but not of selection in causing the observed disequilibrium in the populations of Oc. eatoni.

Genetic Differentiation. The level of genetic differentiation between pairs of geographical populations, estimated by $\mathrm{F}_{\mathrm{ST}}$ and $\mathrm{N}_{\mathrm{m}}$ values (Table 2), clearly shows the differentiation of the Tenerife population from all of the Madeira populations. In the latter group, the population of $\mathrm{ChL}$ (from the center) was significantly differentiated from the southern populations (Cam and Bab) but not from the northern populations $(\mathrm{ChL})$. Pairwise comparisons between populations from the south and north were nonsignificant, except between Bab and Cam.

To measure the overall level of genetic differentiation, the populations were arranged into three groups: 1, all populations (from Canary and Madeira); 2, Madeira populations; and 3, Madeira populations, except the central population $(\mathrm{ChL})$. In group $1, \mathrm{~F}_{\mathrm{ST}}$ values were significant in eight of 10 loci studied whereby the total $F_{\mathrm{ST}}$ value in this group was 0.206 $(P<0.001)$. In group 2 , only four of 10 loci had significant $\mathrm{F}_{\mathrm{ST}}$ values, and although the total value was less than the value observed in group 1 , it still was highly significant $\left(\mathrm{F}_{\mathrm{ST}}=0.050, P<0.001\right)$. Idh locus had a preponderant weight in differentiating Madeira populations from the Tenerife population (Tables 1 and 2 ). In group 3 , the total $\mathrm{F}_{\mathrm{ST}}$ value was not significant $\left(\mathrm{F}_{\mathrm{ST}}=0.026\right.$, N.S. $)$, and only two loci showed significant (with less magnitude) $\mathrm{F}_{\mathrm{ST}}$ values (Table 3; Fig. 2).

The number of effective migrants $(\mathrm{Nm})$ for all loci by $\mathrm{F}_{\mathrm{ST}}$ method and Barton and Slatkin (1986) method was 0.941 and 0.567 , respectively. The estimated Nm 
Table 1. Allelic frequencies and $F_{I S}$ values at 10 enzymes loci in six populations of $O c$. eatoni

\begin{tabular}{|c|c|c|c|c|c|c|}
\hline \multirow{2}{*}{ Locus } & \multicolumn{6}{|c|}{ Pop } \\
\hline & ChR & Cam & $\mathrm{Bab}$ & Que & ChL & Ten \\
\hline \multicolumn{7}{|l|}{ Phi } \\
\hline$(n)$ & 36 & 27 & 32 & 23 & 23 & 27 \\
\hline 100 & 0.944 & 0.944 & 1.000 & 1.000 & 0.739 & 0.815 \\
\hline 102 & 0.042 & 0.056 & 0.000 & 0.000 & 0.196 & 0.185 \\
\hline 105 & 0.014 & 0.000 & 0.000 & 0.000 & 0.065 & 0.000 \\
\hline $\mathrm{F}_{\text {IS }}$ & +0.487 & -0.048 & & & +0.694 & +1 \\
\hline \multicolumn{7}{|l|}{$\mathrm{Ak}$} \\
\hline$(n)$ & 26 & 20 & 21 & 20 & 27 & 28 \\
\hline 100 & 0.981 & 0.889 & 0.971 & 0.900 & 0.963 & 0.875 \\
\hline 106 & 0.019 & 0.111 & 0.029 & 0.100 & 0.018 & 0.107 \\
\hline 110 & 0.000 & 0.000 & 0.000 & 0.000 & 0.018 & 0.018 \\
\hline $\mathrm{F}_{\mathrm{IS}}$ & & -0.097 & & -0.059 & -0.010 & +0.845 \\
\hline \multicolumn{7}{|l|}{ 6-Pdh } \\
\hline$(n)$ & 23 & 30 & 39 & 23 & 23 & 24 \\
\hline 100 & 1.000 & 1.000 & 0.897 & 0.956 & 0.870 & 0.607 \\
\hline 102 & 0.000 & 0.000 & 0.103 & 0.043 & 0.130 & 0.393 \\
\hline $\mathrm{F}_{\mathrm{IS}}$ & & & +1 & +1 & +1 & +0.860 \\
\hline \multicolumn{7}{|l|}{ Got } \\
\hline$(n)$ & 25 & 27 & 21 & 21 & 23 & 34 \\
\hline 98 & 0.020 & 0.000 & 0.000 & 0.000 & 0.044 & 0.235 \\
\hline 100 & 0.980 & 1.000 & 1.000 & 1.000 & 0.956 & 0.768 \\
\hline $\mathrm{F}_{\mathrm{IS}}$ & & & & & +1 & +1 \\
\hline \multicolumn{7}{|l|}{ Pgm } \\
\hline$(n)$ & 26 & 27 & 27 & 21 & 21 & 26 \\
\hline 95 & 0.038 & 0.093 & 0.000 & 0.000 & 0.143 & 0.019 \\
\hline 98 & 0.019 & 0.000 & 0.000 & 0.000 & 0.024 & 0.077 \\
\hline 100 & 0.923 & 0.907 & 1.000 & 1.000 & 0.762 & 0.577 \\
\hline 102 & 0.019 & 0.000 & 0.000 & 0.000 & 0.071 & 0.096 \\
\hline 104 & 0.154 & 0.000 & 0.000 & 0.000 & 0.000 & 0.154 \\
\hline 105 & 0.000 & 0.000 & 0.000 & 0.000 & 0.000 & 0.039 \\
\hline 107 & 0.000 & 0.000 & 0.000 & 0.000 & 0.000 & 0.039 \\
\hline $\mathrm{F}_{\text {IS }}$ & +0.227 & -0.083 & & & +0.533 & +0.401 \\
\hline \multicolumn{7}{|l|}{$\alpha-\mathrm{Gpd}$} \\
\hline$(n)$ & 28 & 33 & 32 & 21 & 27 & 28 \\
\hline 98 & 0.000 & 0.030 & 0.000 & 0.000 & 0.018 & 0.036 \\
\hline 100 & 1.000 & 0.845 & 1.000 & 1.000 & 0.910 & 0.964 \\
\hline 103 & 0.000 & 0.121 & 0.000 & 0.000 & 0.056 & 0.000 \\
\hline 115 & 0.000 & 0.000 & 0.000 & 0.000 & 0.018 & 0.000 \\
\hline $\mathrm{F}_{\mathrm{IS}}$ & & +0.777 & & & +0.373 & -0.019 \\
\hline Idh & & & & & & \\
\hline$(n)$ & 34 & 23 & 29 & 20 & 23 & 31 \\
\hline 90 & 0.000 & 0.000 & 0.000 & 0.000 & 0.000 & 0.323 \\
\hline 95 & 0.000 & 0.000 & 0.000 & 0.000 & 0.000 & 0.549 \\
\hline 100 & 1.000 & 1.000 & 1.000 & 1.000 & 1.000 & 0.129 \\
\hline $\mathrm{F}_{\mathrm{IS}}$ & & & & & & +1 \\
\hline $\mathrm{Me}^{\mathrm{Is}}$ & & & & & & \\
\hline$(n)$ & 39 & 57 & 43 & 23 & 25 & 27 \\
\hline 95 & 0.012 & 0.026 & 0.023 & 0.087 & 0.100 & 0.185 \\
\hline 97 & 0.128 & 0.175 & 0.058 & 0.130 & 0.020 & 0.019 \\
\hline 98 & 0.038 & 0.017 & 0.012 & 0.000 & 0.020 & 0.000 \\
\hline 100 & 0.897 & 0.781 & 0.907 & 0.783 & 0.860 & 0.796 \\
\hline 103 & 0.026 & 0.000 & 0.000 & 0.000 & 0.000 & 0.000 \\
\hline 105 & 0.013 & 0.000 & 0.000 & 0.000 & 0.000 & 0.000 \\
\hline $\mathrm{F}_{\mathrm{IS}}$ & +0.608 & +0.904 & +0.206 & +0.769 & +0.376 & 0.892 \\
\hline $\mathrm{Mdh}$ & & & & & & \\
\hline$(n)$ & 43 & 26 & 31 & 26 & 20 & 32 \\
\hline 97 & 0.012 & 0.019 & 0.000 & 0.000 & 0.029 & 0.406 \\
\hline 100 & 0.965 & 0.942 & 1.000 & 0.961 & 0.941 & 0.594 \\
\hline 103 & 0.023 & 0.019 & 0.000 & 0.038 & 0.029 & 0.000 \\
\hline 105 & 0.000 & 0.019 & 0.000 & 0.000 & 0.000 & 0.000 \\
\hline $\mathrm{F}_{\mathrm{IS}}$ & +0.664 & -0.020 & & +1 & -0.016 & +1 \\
\hline Est & & & & & & \\
\hline$(n)$ & 31 & 26 & 35 & 26 & 21 & 21 \\
\hline 98 & 0.016 & 0.019 & 0.014 & 0.019 & 0.048 & 0.000 \\
\hline 100 & 0.984 & 0.981 & 0.985 & 0.981 & 0.881 & 1.000 \\
\hline 102 & 0.000 & 0.000 & 0.000 & 0.000 & 0.024 & 0.000 \\
\hline 103 & 0.000 & 0.000 & 0.000 & 0.000 & 0.024 & 0.000 \\
\hline 105 & 0.000 & 0.000 & 0.000 & 0.000 & 0.024 & 0.000 \\
\hline $\mathrm{F}_{\mathrm{IS}}$ & & & & & +0.372 & \\
\hline $\mathrm{F}_{\mathrm{IS}}$ total & 0.439 & 0.554 & 0.574 & 0.678 & 0.541 & 0.845 \\
\hline a & 2.4 & 2.2 & 1.6 & 1.6 & 3.1 & 2.5 \\
\hline $\mathrm{p}$ & 27.3 & 63.3 & 18.2 & 18.2 & 77.7 & 72.7 \\
\hline $\mathrm{H}$ & 0.057 & 0.118 & 0.044 & 0.074 & 0.194 & 0.346 \\
\hline
\end{tabular}

$\mathrm{n}$, sample size. a, mean number of alleles per locus; $\mathrm{p}$, percentages of polymorphic loci; $\mathrm{H}$, mean heterozigousity. $\mathrm{F}_{\mathrm{IS}}$, inbreeding coefficient indicating the reduction of heterozygosity due to nonrandom mating. Probability of rejecting HW equilibrium in the case of heterozygotes deficiencies when significant by Bonefferoni correction is shown as corresponding $\mathrm{F}_{\text {IS }}$ in bold. 
Table 2. Pairwise comparison of population differentiation

\begin{tabular}{|c|c|c|c|c|c|c|}
\hline Pop & $\mathrm{ChR}$ & Cam & $\mathrm{Bab}$ & Que & $\mathrm{ChL}$ & Ten \\
\hline ChR & - & 7.814 & 25.25 & 12.25 & 5.702 & 0.500 \\
\hline Cam & $0.031(0.186)$ & - & 4.75 & 49.75 & 6.893 & 0.643 \\
\hline $\mathrm{Bab}$ & $0.012(0.846)$ & $0.050(0.016)$ & - & 27.528 & 3.128 & 0.642 \\
\hline Que & $0.020(0.768)$ & $0.005(0.464)$ & $0.009(0.864)$ & - & 3.987 & 0.630 \\
\hline $\mathrm{ChL}$ & $0.042(0.257)$ & $0.035(0.027)$ & $0.074(0.004)$ & $0.059(0.161)$ & - & 0.975 \\
\hline Ten & $0.333\left(<10^{-6}\right)$ & $0.280\left(<10^{-6}\right)$ & $0.334\left(<10^{-6}\right)$ & $0.284\left(<10^{-6}\right)$ & $0.204\left(<10^{-6}\right)$ & - \\
\hline
\end{tabular}

$\mathrm{F}_{\mathrm{ST}}$ estimates with corresponding $P$ values (in parentheses). Significant values are in bold and presented below the diagonal. Nm estimates are above the diagonal.

and $\mathrm{F}_{\mathrm{ST}}$ values among the populations are given in Fig. 2.

\section{Discussion}

Analysis of genetic variations in Oc. eatoni reveals a substantial and complex population structure across its distribution range. The following sections consider the role of the factors contributing to the observed patterns of genetic variation in this species.

Population Structure and Migration. The $\mathrm{F}_{\mathrm{ST}}$ tests and $\mathrm{Nm}$ estimates identify three subsets of Oc. eatoni populations: 1 , north and south of Madeira; 2 , center of Madeira; and 3, Tenerife. The genetic differentiation data support the clustering of the samples from the north and the south of Madeira into a single panmictic population, distributed across an extended geographical area, and, unusually, displaying a decrease of genetic variation compared with the central population. The geographical distances between the sampling localities in Madeira are small (between 8 and $20 \mathrm{~km}$ ), and no correlation was detected between geographical distances and the level of differentiation. The population from Tenerife was also highly differentiated from the Madeiran populations. $\mathrm{N}_{\mathrm{m}}$ values were very low (less then 1 ) between the populations of the two islands (Table 3). We expect either no or very little gene flow between the populations of the two islands and more gene flow among populations of the same island depending, primarily, on the dispersal rate of the adults. In Oc. eatoni, this rate is unknown, but it has been estimated as $104 \mathrm{~m}$ in A. albopictus (Bonnet and Worchester 1946, Mori 1979) and $580 \mathrm{~m}$ in Ae. aegypti (Reiter et al. 1995). If the dispersal rate in Oc. eatoni is similar to these two species, its role in homogenizing the populations of the island will depend on the availability of breeding sites.

Human activity and trade also have played an important role in spreading mosquitoes from their place of origin to other parts of the world (Smith 1956, Craven et al. 1988, Peyton et al. 1999). However, the ability of species to colonize a new or a different ecological condition should be the reason behind their geographical distribution.

Population Fragmentation, Seasonal Changes, and Human Activities. Madeiran habitats are highly heterogeneous; annual precipitation and temperature vary greatly from area to area because of the presence of microclimates around the island. The central peaks of the island register the lowest annual temperature and highest annual precipitation. Southern Madeira has a drier climate, compared with the northern and central areas. The lack of genetic differentiation among the southern/northern populations may result from population fragmentation and reduced breeding site availability in less humid areas during the dry seasons. Conversely, breeding sites in the more humid areas are expected to remain almost intact throughout the year. This fragmentation may cause local isolation, decreasing effective population size and permitting drift to influence genetic structure, resulting in the fixation of the most common alleles in some populations and reduction or elimination of the less common alleles in others. This may explain the observed pattern of genetic variation for the majority of loci (AK, 6-Pdh, Got, $\alpha$-Gpd, Got, Me, Mdh, and Est). However, it is unlikely that drift alone determines the observed allelic frequencies in the Phi and Pgm. Also, it is unlikely that random processes fixed only the same allele in each of the two loci in the samples from the north and south. Phi and Pgm were the two loci showing linkage disequilibrium, although Ohta's test revealed that drift and not selection was the cause of disequilibrium.

Sampling period is another factor that can contribute to perceived differences in genetic variability among the populations. Temporal control of genetic structure has been reported for populations of $\mathrm{Ae}$.

Table 3. F-statistic as a measure of population differentiation

\begin{tabular}{|c|c|c|c|c|c|c|c|c|c|c|c|}
\hline Group & Phi & $\mathrm{Ak}$ & Pgd & Got & Pgm & Gpd & Idh & $\mathrm{Me}$ & Mdh & Est & Total \\
\hline 1 & $\begin{array}{c}0.100 \\
* * *\end{array}$ & 0.028 & $\begin{array}{c}0.183 \\
\text { *** }\end{array}$ & $\begin{array}{l}0.151 \\
* * *\end{array}$ & $\begin{array}{c}0.122 \\
\text { *** }\end{array}$ & $\begin{array}{c}0.050 \\
* * *\end{array}$ & $\begin{array}{c}0.620 \\
* * *\end{array}$ & $\begin{array}{c}0.037 \\
* * *\end{array}$ & $\begin{array}{l}0.238 \\
* * *\end{array}$ & 0.033 & $\begin{array}{c}0.206 \\
\text { *** }\end{array}$ \\
\hline 2 & $\begin{array}{c}0.111 \\
* * *\end{array}$ & 0.013 & 0.054 & 0.024 & $\begin{array}{c}0.074 \\
* * *\end{array}$ & $\begin{array}{c}0.055 \\
* *\end{array}$ & & $\begin{array}{c}0.031 \\
* * *\end{array}$ & 0.011 & 0.012 & $\begin{array}{c}0.050 \\
* * *\end{array}$ \\
\hline 3 & 0.011 & 0.017 & 0.032 & -0.001 & $\begin{array}{c}0.033 \\
*\end{array}$ & $\begin{array}{c}0.094 \\
*\end{array}$ & & 0.022 & -0.009 & -0.017 & 0.026 \\
\hline
\end{tabular}

Group 1, all populations; group 2, all Madeira populations; and group 3, Madeira populations except ChL. 


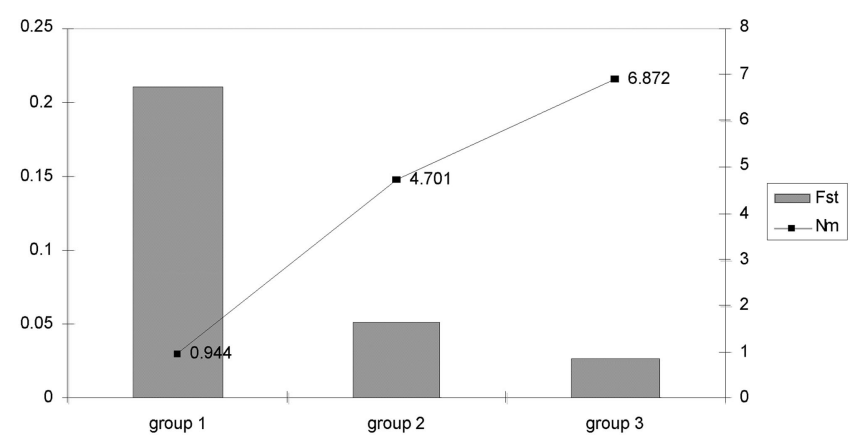

Fig. 2. Comparison of FST and Nm values in three groups of the populations. Group 1, all populations; group 2, populations from the Madeira Island; and group 3, Madeira populations except ChL.

albopictus and Ae. aegypti (Kambhampati et al. 1990, Huber et al. 2002). Samples of Oc. eatoni from the central population of Madeira were collected in winter (average monthly precipitation of $12.5 \mathrm{~mm}$ ), whereas all other populations were collected in the summer (average monthly precipitation of $1.5 \mathrm{~mm}$ ) (Portela et al. 2002). The Tenerife population was sampled in January. Thus, the two structured populations were sampled in the wetter and colder seasons from humid areas.

The application of insecticides also may contribute to the genetic variation observed in Oc. eatoni. The indigenous laurisilva forest of Madeira is protected. Some areas are pristine and undisturbed, whereas small agricultural villages are found in other areas, particularly on the periphery of the forest. The central population and one of the northern populations (Que) are located in protected areas of laurisilva with no nearby human habitation. The remaining three populations were situated in unprotected areas with high or moderate levels of habitation and agricultural activity. Extinction and recolonization can play important roles in determining the genetic structure of the populations, especially in small geographic areas (Yan et al. 1998). Therefore, insecticide application may contribute to reduced variability in some of the populations because suitable niches are first vacated and then reoccupied by mosquitoes after insecticide application. The population from Tenerife was collected from a mountainous area of laurisilva forest (much less dense than that found on Madeira) with no apparent human activity. Therefore, seasonal variation and insecticides seem to be important in shaping the pattern of genetic variation.

Dispersion and abundance of the blood source have an important influence in mosquito population structure. The source of blood that Oc. eatoni feeds upon remains unknown, and the influence of this phenomenon on Oc. eatoni populations merits further study.

Breeding and Genetic Structures. All populations, except Que, showed total heterozygote deficiencies measured by $\mathrm{F}_{\text {IS }}$ values (Table 1 ). Inbreeding can cause heterozygote deficits and is expected to affect all the loci. Our study indicated that inbreeding acts strongly upon the Tenerife population but was less marked in the Madeiran populations. Heterozygote deficiency also could be explained by Wahlund's effect in subdivided populations. This effect is expected to occur in case of population admixture with differentiated loci but not with nondifferentiated loci. Therefore, Wahlund's effect does not seem to be consistent with the present data.

Confined to two Macaronesian Islands, Oc. eatoni has a small population size but displays exceptionally high genetic differentiation not only between island populations but also within island populations (Madeira). A higher level of genetic variability would be expected if molecular markers other than the ones used in the current study were applied. For example, genetic differentiation between populations of $\mathrm{Ae}$. aegypti from Cambodia was found to be 3 to 5 times higher using amplified fragment length polymorphic compared with isoenzyme markers (Paupy et al. 2004).

Speciation and Colonization. Oc. eatoni is an example of one speciation event followed at least by one colonization event. The geographical origin of this species cannot be inferred from this study. However, based on the detected genetic variability, we can conclude that the colonization process was not marked by founder effect. Had this been the case, migration would have continued between the populations of the two islands partially facilitated by Man via the trade routes between Madeira and Canary Islands, established since the fifteenth century (Ribeiro 1997). This is unlikely, however, given the patchy distribution of Oc. eatoni, particularly in the Canary Islands, where it is confined to two distant localities (Baez 1987).

\section{Acknowledgments}

We thank Humberto Quesada for the valuable comments and Roberto Camacho and Jane Spinola for technical assistance. We also thank to Samantha Jane Hughes for revising the text. This work was supported by a Fundação para a Ciência e Tecnologia (FCT)/Lisbon, grant (PRAXIS/2/2.1/ BIA/283/94) to R.C. and the Centre of Macaronesian Studies. 


\section{References Cited}

Apostol, B. L., W. C. Black, P. Reiter, and B. R. Miller. 1996. Population genetics with RAPD-PCR markers: the breeding structure of Aedes aegypti in Puerto Rico. Heredity 76: 325-334

Baez, M. 1987. Atlas preliminary de los mosquitos de las Islas Canarias (Diptera, Culicidae). Vieraea 17: 193-202.

Bonnet, D. D., and D. J. Worchester. 1946. The dispersal of Aedes albopictus in the territory of Hawaii. Am. J. Trop. Med. 26: 465-476.

Barton, N. H., and M. Slatkin. 1986. A quasi-equilibrium of the distribution of rare alleles in a subdivided population. Heredity 56: 409-415.

Capela, R. A. 1981. Contribution to the study of mosquitoes (Diptera: Culicidae) from the Archipelagos of Madeira and the Salvagens. I Madeira. Arquivos do Museu Bocage 1: $47-52$.

Calvero, G. 1947. Aedes (Finlayua) eatoni Theoblad, nuevo aedino tinerfeño. Revista de Sanidad e Higiene Pública 21: $429-432$

Cook, S., M. Diallo, A. A. Sall, A. Cooper, and E. C. Holmes. 2005. mitochondrial markers for molecular identification of Aedes mosquitoes (Diptera: Culicidae) involved in transmission of arboviral disease in west Africa. J. Med. Entomol. 42: 19-28.

Craven, R. B., D. A. Eliason, D. B. Eliason, P. Reiter, E. G. Campos, E. L. Jakob, G. C. Smith, C. J. Bozzi, C. G. Morre, G. Mauping, et al. 1988. Importation of Aedes albopictus and exotic mosquito species into the United States in Used tires from Asia. J. Am. Mosq. Control Assoc. 4: 138-142.

Edwards, F. W. 1916. Ochlerotatus eatoni, sp. n. Bull. Entomol. Res. 6: 358.

Fisher, R. A. 1970. Statistical methods for research workers, 4th ed. Oliver \& Boyd, Edinburgh, Scotland.

Forattini, O. P. 1986. Identificaçao de Aedes (Stegomyia) albopictus no Brasil. Ver. Saude Publ., São Paula 20: 244 245.

Giming, J. E. 2000. Genetics and morphological variation in three snow pool Aedes mosquito species of subgenus Ochlerotatus (Diptera: Culicidae). J. Med. Entomol. 37: 902-908.

Guo, S. W., and E. A. Thompson. 1992. Performing the exact test of Hardy-Weinberg proportion for multiple alleles. Biometrics 48: 361-372.

Hawley, W. A. 1988. The biology of Aedes albopictus. J. Am. Mosq. Control Assoc. (Suppl. 1): 1-40.

Huber, K., L. L. Loan, T. H. Hoang, T. K. Tien, F. Rodhain, and A.-B., Failloux. 2002. Temporal genetic variation in Aedes aegypti populations in Ho Chi Minh City (Vietnam). Heredity 89: 7-14

Kambhampati, S., W. C. Black, K. S. Rai, and D. Sprenger 1990. Temporal variation in genetic structure of a colonising species: Aedes albopictus in the United States. Heredity 64: 281-287.

Loukas, M., and C. B. Krimbas. 1980. Isozyme techniques in D. subobscura. Drosophila Info. Serv. 55: 157-158.

Mori, M. 1979. Effects of larval density and nutrition on some attributes of immature and adult Aedes albopictus Trop. Med. 21: 85-103.

Ohta, T. 1982. Linkage disequilibruim due to random genetic drift in finite subdivided populations. Proc. Natl. Acad. Sci. U.S.A. 79: 1940-1944.

Paupy, C., A. Orsoni. L. Mousson, and K. Huber. 2004. Comparison of amplified fragment length polymorphism (AFLP), microsatellite, and isoenzyme markers: popula- tion genetics of Aedes aegypti (Diptera: Culicidae) from Phnom Penh (Cambodia). J. Med. Entomol. 41: 664-671.

Peyton, E. L., S. R. Campbell, C.T.M. Candeletti, M. Romanowski, and W. J. Crans. 1999. Aedes (Finlaya) japonicus japonicus (Theobald), a new introduction into the United States. J. Am. Mosq. Control Assoc. 15: 328 241.

Portela, M. M., M. Gaspar, and G. R. Hora. 2002. Avaliação do escoamento anual médio na Ilha da Madeira. Tecnologia da Àgua, Edição II: 50-58.

Powell, J. R., W. J. Tabachnick, and J. Arnold. 1980. Genetics and the origin of a vector population: Aedes aegypti, a case study. Science (Wash. DC) 208: 1385-1387.

Rai, K. S. 1991. Aedes albopictus in the Americas. Annu. Rev. Entomol. 36: 459-484.

Raymond, M., and F. Roussett. 1995. GENEPOP (version $1.2)$ : population genetics software for exact tests an ecumenicism. J. Hered. 86: 248-249.

Reinert, J. F. 2000. New classification for the composite genus Aedes (Diptera: Culicidae: Aedini), elevation of subgenus Ochlerotatus to generic rank, reclassification of the other subgenera, and notes on certain subgenera and species. J. Am. Mosq. Control Assoc. 16: 175-188.

Reiter, P., M. Amador, R. Anderson, and G. G. Clark. 1995. Dispersal of Aedes aegypti in an urban area after blood feeding as demonstrated by rubidium-marked eggs. Am. J Trop. Med. Hyg. 52: 177-179.

Rey, D., L. Despres, F. Schaffner, and J. C. Meyran. 2001. Mapping of resistance to vegetable polyphenols among Aedes taxa (Diptera, Culicidae) on a molecular phylogeny. Phylogenet. Evol. 19: 317-325.

Ribeiro, J. A. 1997. O relacionamento da Madeira com Lançarote-Forteventura no período Filipino (ArrecifeCanárias). Journadas Internacionais de LançaroteForteventura, Actas 4: 177-192.

Rousett, F., and M. Raymond. 1995. Testing heterozygote excess and deficiency. Genetics 140: 1413-1419.

Schaffner, E.G.A., B. Geoffroy, J.J.P. Hery, A. Rhaiem, and J. Brunhes. 2001. The mosquitoes of Europe. IRD Éditiors. IRD, Montpellier, France.

Smith, C.E.G. 1956. The history of dengue in tropical Asia and its probable relationship to the mosquito Aedes aegypti. J. Trop. Med. Hyg. 59: 243-251.

Taafe Gaunt, M. C., J.-P. Mutebi, and L. E. Munstermann. 2004. Biochemical taxonomy and enzyme electrophoretic profiles during development, for three morphologically similar Aedes species (Diptera: Culicidae) of the subgenus Stegomyia. J. Med. Entomol. 41: 23-32.

Tabachinck, W. J., and G. P. Wallis. 1985. Population genetics structure of yellow fever mosquito Aedes aegypti in Caribbean: ecological considerations, pp. 371-382. In L. P. Lounibos, J. R. Rey, and J. H. Frank [eds.], Ecology of Mosquitoes: Proceeding of a Workshop, January 1984 Florida Medical Entomology Laboratory, Vero Beach, FL.

Weir, B. S., and C. C. Cockerham. 1984. Estimating F-statistics for the analysis of population structure. Evolution 38: $1358-1370$

Wright S. 1969. Evolution and the genetics of populations vol. 2. The theory of gene frequencies. University of Chicago Press, Chicago, IL

Yan, G., D. D. Chadee, and D. W. Severson. 1998. Evidence for genetic hitchhiking effect associated with insecticide resistance in Aedes aegypti. Genetics 148: 793-800.

Received 27 March 2005; accepted 21 September 2005. 